\title{
Biosensors Based on Gold Nanostructures
}

\author{
Marcio Vidotti, ${ }^{*, a}$ Rafaela F. Carvalhal, ${ }^{b}$ Renata K. Mendes, ${ }^{b}$ Danielle C. M. Ferreira ${ }^{b}$ \\ and Lauro T. Kubota ${ }^{b}$
}

${ }^{a}$ Departamento de Química, Universidade Federal do Paraná, CP 19081, 81531-980 Curitiba-PR, Brazil

${ }^{b}$ Instituto de Química and Instituto Nacional de Ciência e Tecnologia de Bioanalítica, Universidade Estadual de Campinas, CP 6154, 13083-970, Campinas-SP, Brazil

\begin{abstract}
O presente trabalho de revisão aborda os mais recentes avanços na tecnologia de biossensores alcançados através da montagem de biomoléculas associada com nanopartículas de ouro na construção de dispositivos analíticos. Esta revisão está dividida de acordo com a biomolécula empregada no desenvolvimento de biossensores: (i) compostos imunológicos; (ii) DNA/RNA funcionais; e (iii) enzimas e proteínas Heme. A fim de facilitar a compreensão, cada seção foi subdividida de acordo com o modo de transdução. Os imunossensores contendo nanopartículas de ouro têm uma ampla gama de aplicações nos campos alimentício, ambiental, farmacêutico, químico e de diagnósticos clínicos. As nanopartículas foram empregadas para melhorar o sinal analítico ou a imobilização dos imunocompostos. Em outra seção, os biossensores DNA/ RNA empregando nanoestruturas de ouro como labels e biossensores label-free associados a nanoestruturas de ouro como transdutores foram sistematicamente relatados para a rápida identificação de patógenos, espécies de interesse ambiental e diagnóstico clínico. A inclusão de nanopartículas de ouro em eletrodos modificados aumenta a transferência de elétrons entre o transdutor e a biomolécula proporcionando um melhor desempenho quando enzimas e proteínas redox heme são usados. Biossensores para a detecção e quantificação de glicose e peróxido de hidrogênio foram também discutidos.
\end{abstract}

The present review discusses the latest advances in biosensor technology achieved by the assembly of biomolecules associated with gold nanoparticles in analytical devices. This review is divided in sections according to the biomolecule employed in the biosensor development: (i) immunocompounds; (ii) DNA/RNA and functional DNA/RNA; and (iii) enzymes and Heme proteins. In order to facilitate the comprehension each section was subdivided according to the transduction mode. Gold nanoparticles based immunosensors have a wide range of applications in food, environmental, pharmaceutical, chemistry and clinical diagnostics. The nanoparticles were employed to improve whether the analytical signal or the immunocompounds immobilization. In another section, biosensors based on DNA/RNA biomolecules employing gold nanostructures as labels and label-free funtional DNA/RNA biosensors associated to gold nanostructures as tranducers were systematically reported for rapid identification of pathogens, species of environmental interest and clinical diagnostics, respectively. The inclusion of gold nanoparticles in modified electrodes itself enhances the electron transfer between the transducer and biomolecules leading to improved bioanalytical devices when redox enzymes and heme proteins are used. Biosensors for the detection and quantification of glucose and hydrogen peroxide are discussed as well.

Keywords: gold nanoparticles, biosensors, bioanalytical devices, nanotechnology, biomolecules

\section{Introduction}

In the past few years an intensive effort has been done in the field of analytical science aiming the

\footnotetext{
*e-mail: mvidotti@ufpr.br
}

development of materials at nanometric scale and their intrinsic properties. In fact, two different phenomena can occur when the crystallite size of inorganic materials are reduced at nanometers dimensions, the first is called quantum size effect and it occurs when the material shows a drastic change in its physical-chemical 
properties, such as the blue-shift presented by some semiconductors nanoparticles. ${ }^{1-3}$ The second feature is due to the huge relationship between surface area and volume, ${ }^{4-6}$ being more interesting for electroanalytical purposes. Among the nanomaterials, gold has a special role. Many synthetic procedures can be found in the literature in order to control the size, monodispersion, morphology and surface chemistry of gold nanoparticles (AuNPs). The easy modification of gold surface by thiol ended molecules makes then suitable for many different biological assemblies. ${ }^{7-9}$

Nanostructures present several advantages in analytical sciences when used as transducers or as a component of the recognition layer in a macrosized sensing device. In the first case, the intrinsic properties of AuNPs, when used as transducers, several improvements are achieved such as mass transport, more availability of reactional sites, aggregation/dispersion optical effect and the increase of optical signal due to localized surface plasmon resonant properties of such added nanoparticles can be explored. In the later case, the improvement of the biosensor response can be achieved by the increase of the area/ volume relationship that increases the number of attached biocomponent in the sensing surface.

As mentioned above, one interesting point concerning AuNPs is related to the well known surface plasmon band (SPB), which consists in a broad absorption band in the visible region around $520 \mathrm{~nm} .{ }^{9-12}$ This band is due to collective oscillations of the electrons at the conduction band on the nanoparticle surface, which provides considerable information of the band structure in metals. This property has been a subject of many studies of optical spectroscopy properties. ${ }^{13}$

Nanoparticles have high surface areas and unique physical-chemical properties that can be easily tuned, making them ideal candidates for developing biosensing devices. ${ }^{14-16}$ AuNPs obtained from commercial sources or conveniently produced in laboratories have attracted much attention in biological studies owing to their low toxicity, biocompatibility and unique optical properties. Biological tests measuring the presence or activity of selected analytes become quicker, more sensitive and flexible when nanoscale particles are put together, with numerous advantages over more traditional procedures.

Accordingly to earlier definitions, the biological recognition element of a biosensor ought to be of biological origin as an enzyme, an antibody, an antigen, a cell, a tissue, a DNA (deoxyribonucleic acid). However, not all recognition agents in novel devices are of biological origin, but synthetically produced elements such as crown ethers, cryptands, calixarenes and molecularly imprinted polymers. The IUPAC (International Union of Pure and Applied Chemistry) had recommended that "the biological recognition element may be based on a chemical reaction catalysed by, or on equilibrium with, macromolecules that have been isolated, engineered or are present in their original biological environment". ${ }^{17,18}$ The main objective on the utilization of biomolecules lies on the high selectivity for the analyte, where higher sensitivities can be reached by the development of new and effective transducers. In this sense, the utilization of nanostructured materials brought a new and exciting perspective to analytical sciences.

In present review, some of the latest advances in recognizing plataforms modification by using gold nanostructures and biomolecules assemblies are shown aiming the biosensor development. In Scheme 1 the organization of the present paper is shown: the biological detection element was subdivided in four classes such as redox proteins, immunocompounds, DNA/RNA-based (RNA: ribonucleic acid) molecules and other biomolecules. Each section is going to be organized according to the transduction element that was employed to prepare the biosensor. At Scheme 1 is summarized the effects and the role of AuNPs in the biosensor performance.

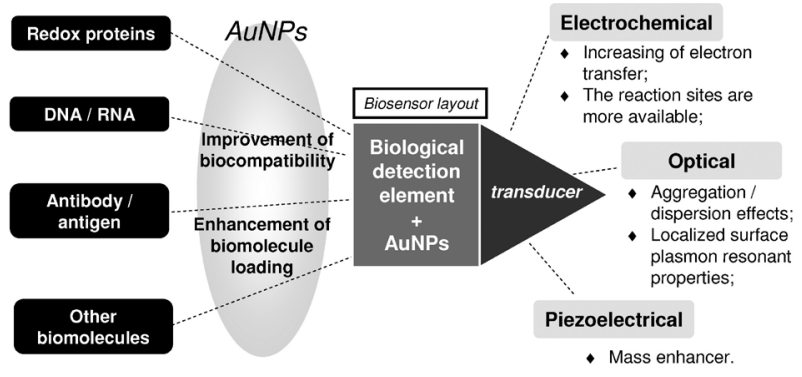

Scheme 1. Representation of the use of AuNPs in the biosensors.

\section{Immunosensors Based on AuNPs}

The principle of the immunosensor takes into account the specific reaction between antibody and antigen performed on appropriate transducers. Immunosensors have a wide range of applications in food, environment, pharmaceutical, chemistry and clinical diagnostics, and one of the most important points relies on the appropriate choice of the immobilization method. ${ }^{19}$ In recent years, various nanomaterials with physical and chemical properties have been applied to achieve improved immobilization of immunocompounds. The use of AuNPs on immunosensor development has recently received much attention ${ }^{20-24}$ being the electrochemical, piezoelectric and optical the most studied transducers. 


\subsection{Optical}

AuNPs have been used as a platform for the biomolecule immobilization, but their interactions with light makes possible to employ them to analytical purposes. The optical properties of nanoparticles changes according to their size and shape leading to different absorption bands. For example, gold nanorods have two principal plasmon absorption bands that are observed in the visible region of the electromagnetic spectra, these bands are related to the orientation of the rods. This characteristic was employed to the determination of human immunoglobulin $\mathrm{G}(\mathrm{IgG})$, which is used as a protein model by Wang et al. ${ }^{25}$ The authors have detected IgG by using silica-coated gold nanorods deposited on poly(4-vinylpyridine) (PVP) film on quartz substrates. The subsequent covalent bioconjugation of amino-functionalized gold nanorods-silica films with goat anti-human IgG is employed for the optical detection of antigen once there is a gradual absorbance change as the antigen concentration increases. The immunosensor demonstrated good sensitivity with color changes being observable by the naked eye.

Another work involving the human IgG optical detection employs the protein A, which is a cell wall component of Staphylococcal aureus that binds specifically to the $\mathrm{Fc}$ portion of $\operatorname{IgG}$ (anti-protein A) from many mammals. ${ }^{26}$ For optical immunosensor construction, avidin was added in the biotin modified cuvette, and then injected AuNPs, followed by the injection of protein $\mathrm{A}$ for oriented immobilization of human $\operatorname{IgG}$ on the cuvette surface of the resonant mirror. Avidin, in the $\mathrm{pH}$ used, is positively charged allowing the electrostatic binding with negatively charged AuNPs. The method shows good reproducibility with a detection limit of $8.7 \mu \mathrm{g} \mathrm{mL}^{-1}$.

Using the specificity binding between protein A and $\mathrm{IgG}$, Lin et al. ${ }^{27}$ developed an immunosensor based on AuNPs and employing surface-enhanced Raman scattering (SERS) technique. The preparation of immunoassay substrate was based on three steps, as illustrated in Figure 1. The elastomer polydimethylsiloxane (PDMS) film was formed on silicon wafer to create holes templates. After that, the PDMS cover and a glass slide with gold film were aligned and bonded together. In the last step, the IgG solution was pipetted onto each PDMS-surrounded gold well. For SERS assay, AuNPs were labeled with 5,5'-dithiobis(2-nitrobenzoic acid), which is a Ramanactive molecule, followed by $\operatorname{IgG}$ immobilization. The Raman scattering increases as a function of the number of modified-AuNPs link to protein A in the well. The SERSbased immunoassay was performed using a sandwich method and the detection limit was $1 \mathrm{pg} \mathrm{mL}^{-1}$.
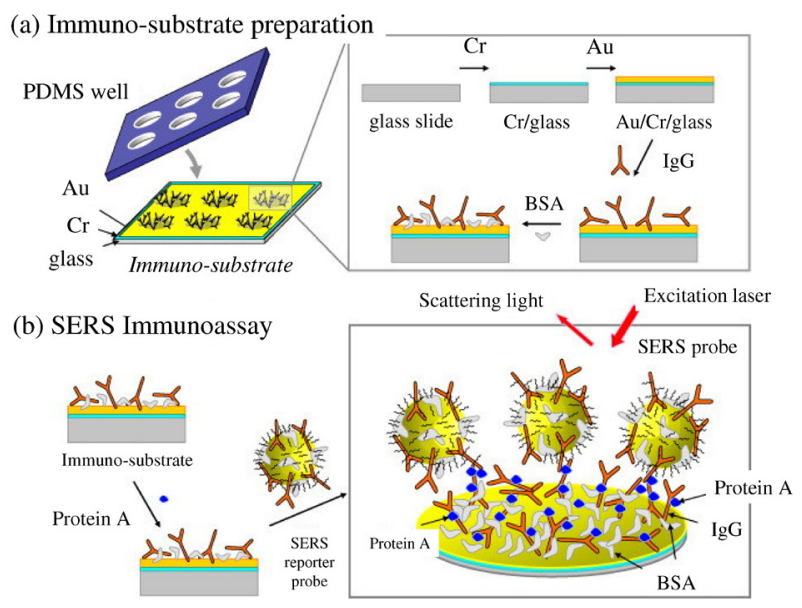

Figure 1. Preparation processes of SERS-based immunoassay. (a) IgG is immobilized on the self-designed immunosubstrate and (b) the illustration of the sandwich interaction among the Raman reporter labeled immunoAuNP, the antigen, and the immunosubstrate. Reprinted with permission (Elsevier) from reference 27.

Noble metal nano-structures presenting localized surface plasmon have recently shown to be suited for immunosensor purposes. This feature is advantageous when compared to conventional flat extended film formed in surface plasmon resonance (SPR) systems due to the simplicity of the optical configuration and the enhanced oscillation of charge density between a metal substrate and the nanoparticle adlayer, since this oscillation is related to electromagnetic coupling of particle-particle and particle-substrate, strongly depends on particle size, particle distribution, distance between particle and substrate, shape of the nanoparticle and the type of substrate such as $\mathrm{Pt}, \mathrm{Ag}$ and $\mathrm{Au}^{28}$

An interesting application using this localized SPR technique is the quantitative determination of stanozolol, which is a doping substance, was enhanced by using the immunosensor based on AuNPs associated to SPR technique. ${ }^{29}$ In addition, the active area of AuNPs decreases the minimum detectable number of molecules involved in the binding event, so in this case the detection limit reaches sensing down to pmol L ${ }^{-1}$. Another work that emphasizes this improvement of SPR response is described by Kawaguchi et al. ${ }^{30}$ for TNT (trinitrotoluene) detection. The assay format of indirect competitive inhibition was used for the determination of TNT in the immunoreaction of the trinitrophenol- $\beta$-alanine immobilized via covalent bound by using poly(ethylene glycol) hydrazinehydrochloride $\left(\right.$ PEG-NH ${ }_{2}$ ) on AuNPs. Studies showed that the shift off resonance angle was approximately four times higher than those ones without AuNPs with a detection limit of $10 \mathrm{ppt}$ for TNT. Another work employs AuNPs to construct a SPR immunosensor for detection of fibronectin by using the antibody immobilized on SAM (self-assembled monolayer) 
modified gold disk. ${ }^{31}$ The biomolecule was determined by the methods of direct, sandwich and colloidal Au-enhanced immunoassays and the results were compared. The concentration range of fibronectin is higher when AuNPs are used on the immunosensor construction.

By employing another SPR immunoassay, a labelfree biosensor was prepared by the spontaneous antibody immobilization on AuNPs trapped on poly-ophenylenediamine nonconducting film was used to detect IgG. ${ }^{32}$ The film was electropolymerized on gold substrate and the AuNPs were assembled on the modified surface. Antibody molecules were adsorbed on surface to fabricate the immunoassay interface. The results demonstrated that AuNPs were uniformly dispersed on the porous surface of film, which formed a nano-structure biocompatible interface and a sensitive device for antigen determination with a detection limit of $1 \mu \mathrm{g} \mathrm{mL} \mathrm{m}^{-1}$.

\subsection{Electrochemical}

Electrochemical methods have been used in immunoassay due to their significant advantages over other approaches such as simple treatment procedure, inexpensive instrumentation, higher sensitivities, automated detection, easy handling for miniaturization and short detection times. For any electrochemical immunoassay protocol based on AuNPs the biocomponent immobilized has to maintain its bioactivity, a key factor for these measurements. The most of the works involving immunosensors is related to the diagnosis and/or monitoring of human diseases. The carcinoembryonic antigen is a protein used as tumor marker and has been frequently investigated in immunoreactions. A label-free amperometric immunosensor was fabricated by $\mathrm{Ou}$ et $a l .{ }^{33}$ on a mercaptopropanesulfonic modified gold electrode surface based on LbL (layer-by-layer) assembly of AuNPs, multi-walled carbon nanotubes-thionine (MWCNT-Thi) and chitosan (Chit), \{AuNPs/ MWCNTThi/Chit $\}_{n}$, and posterior anti-CEA immobilization via covalent bound. The detection is based on the variation of current responses before and after the immunoreaction. When the immobilized antibodies have bound with antigens, the antigen-antibody complex formed on the surface inhibited the electron-transfer. Since the formed film by LbL presents an electroative profile, the modified electrode amperometric signal can be modulated by subsequent addition of target molecules. Then, it was verified a decrease of the amperometric signal as the concentration of antigen on surface increases. In another work, the CEA was determined by using a new amperometric immunosensor formed by nano- $\mathrm{Fe}_{3} \mathrm{O}_{4}$ modified carbon paste electrodes. The $\mathrm{Fe}_{3} \mathrm{O}_{4}$ nanoparticles were employed due to their magnetic behavior avoidong the leaking of the functionalized nanoparticle from the composite electrode. Furthermore, the hydroxyl groups on the $\mathrm{Fe}_{3} \mathrm{O}_{4}$ surface were chemically modified with (3-mercaptopropyl)trimethoxysilane in order to attach the AuNPs / biomolecules. These modifications provided an improvement of the electrochemical signal. ${ }^{34}$ As widely reported, the AuNPs provided a high superficial biocompatible plataform for CEA immobilization. The immunoassay was performed using a (horseradish peroxidase) HRP-labeled anti-CEA presents in solution.

Immunosensors based on AuNPs have been also employed in the agriculture field due to the high sensitivity when compared to other biosensors. Besides, immunoanalysis performed with biosensor are easier and faster than the conventional immunoassay methods, as radioimmunoassay (RAI) and enzyme-linked immunosorbent assay (ELISA), in which sample pretreatments are usually required. An interesting work was carried out by Tang et al. ${ }^{35}$ who developed an electrochemical immunosensor for picloran (which is a widely used herbicide), using a substrate based on chitosanAuNPs disposable membrane. The AuNPs offered a large biocompatible specific surface which have retained the bioactivity of immunocompound and promoted the electron transfer with the immobilized biomolecule. This strategy was employed in order to solve the regeneration inefficiency of the electrode surface after continuous use.

Another work developed for agricultural application was described by Valera et al. ${ }^{36}$ which described an immunosensor for indirect conductimetric analysis of atrazine using an interdigitated microelectrode protected with $\mathrm{N}$-acetylcysteamine and the pyrex substrate between the electrodes was modified with 3-glycidoxylpropyl trimethoxysilane (GPTS). The last one was used as an anchor to antigen (pesticide) followed by antibody immobilization. In order to generate the conductance signal, a secondary antibody-labelled with AuNPs was added upon the sensor surface. These kinds of electrodes array provide the possibility to obtain several replicates per assay. The use of AuNPs-labeled antibodies makes possible the antigen detection by means of simple DC (direct current) measurements.

AuNPs-based immunosensors for food analysis can be also found in the literature. An interesting work describes the detection of Escherichia coli in milk samples. ${ }^{37}$ In this work, a disposable amperometric immunosensor was developed by using a screen printed carbon electrode modified with ferrocenedicarboxylic acid and AuNPs which lead to increase in the amount of anti-E.coli immobilized on electrode surface, achieving high sensitivity. The anti E. coli 
was immobilized via cross-linking by using glutaraldehyde and after adsorption of antigen, a second HRP-labeled antibody was immobilized.

A novel experimental method for label-free detection of human IgG was proposed by Zhang et al. ${ }^{38}$ by immobilizing antibody on AuNPs/L-cysteine coated electrode using differential pulse voltammetry (DPV) for analysis. Due to the presence of AuNPs the modified electrode exhibited an excellent electrochemical behavior toward the oxidation of dopamine (DA). Therefore, when the immobilized antibody is reacted with antigen in serum, they form a dense immunocomplex film. As a result the voltammetric response to DA decreases as the antigen concentration increases and the immunological reaction can be detected. The immunosensor showed a high stability and sensitivity with a detection limit of $0.25 \mathrm{ng} \mathrm{mL}^{-1}$.

\subsection{Piezoelectric}

The combination of QCM-based (quartz crystal microbalance) biosensors and AuNPs is a promising methodology of enhancement of the sensor response. The nanoparticle layer provides a three-dimentional architecture and increases the surface area, which can accommodate more ligand-molecules so by this way more target analytes can be attached. An interesting work that illustrates this behavior is related to the detection of antithrombin III by using a biosensor based on "in situ" growth of AuNPs on the electrode employing QCM technique. Heparin was immobilized on AuNPs by cysteamine self-assembledmonolayer (SAM). The frequency changes of antithrombinheparin interaction were higher in AuNP "in situ" grown sensor than nanogold adsorption immunosensor. ${ }^{39}$

A reusable piezoelectric immunosensor using magnetic hydroxyapatite (HAP) nanocrystals embedded with $\gamma-\mathrm{Fe}_{2} \mathrm{O}_{3}$ and colloidal AuNPs for antibody immobilization is another example of human IgG detection. ${ }^{40}$ The capture of IgG was carried out in a homogeneous bulk solution. Subsequently, the immunocomplexes formed were introduced into a laboratory-made detection vessel for magnetic-separation QCM measurement, where the immunosensor regeneration could be accomplished by canceling the magnetic field. The nanocomposites provided a large loading capacity of biomolecules maintaining the well-preserved bioactivity, also the immunocompound structure exposed possess a good degree of flexibility and accessibility to the analyte.

In general, the use of AuNPs in immunosensors as versatile and efficient substrates for antigen or antibodies immobilization showed not only the increased amount of adsorbed biomolecules on the metallic surface, but also the preservation of immunoactivity. Additionally, the AuNPs can be used for enhancing the immunoreaction signals and improving the sensitivity.

\section{Biosensors Based on AuNPs and DNA/RNA Molecules}

DNA can be used as well-characterized and controllable macromolecule in nanomaterials for programmable selfassembly, using the selective affinity of DNA pairs strands to form DNA nanostructures. ${ }^{41}$ Detection of specific oligonucleotide sequences has important applications in medical research and diagnosis, besides the monitoring of environment and food and drug industries as well. Fluorescence-based DNA assays are the most widely used, but suffer from the presence of autofluorescence in some biological samples and substrates. ${ }^{42}$

The main useful feature of DNA as a linking agent is the variety of available sequences combined with the specificity of base pairing. In fact, each different sequence acts as an independent linker. If a set of proteins is conjugated to a corresponding set of target ssDNA sequences, and a surface is patterned with the appropriate complementary oligonucleotide probes, sequence-specific hybridization will direct the target conjugates to the appropriate spots on the surface. ${ }^{43,44}$ It is important to emphasize that double and single-stranded oligonucleotides (dsDNA and ssDNA) have different electrostatic properties, because ssDNA can uncoil to expose its bases, whereas dsDNA has a stable double-helix geometry that always presents the negatively charged phosphate backbone. ${ }^{45}$

Numerous methods have been developed for identifying DNA-nanoparticle labels at array surfaces, including optical absorbance, light scattering, spectral and SPR shifts, electrical and electrochemical signals, and gravimetry. All of these procedures offer different advantages to the detection of specific DNA sequence targets.

\subsection{Optical}

AuNPs-based diagnostics can happen by utilization of the color change of AuNPs upon aggregation, the best characterized example is the AuNPs functionalized with oligonucleotides which is able to specifically hybridize to a complementary target for the detection of specific nucleic acid sequences in biological samples. ${ }^{46}$ The optical properties of three-dimensional aggregations of AuNPs have been used to detect hybridization of specific DNA sequences in solution and on surfaces as an alternative to fluorescent labeling of DNA. ${ }^{47}$ The use of AuNPs and DNA can potentially translate into new assays that improve on current methods of DNA detection. 
The use of oligonucleotide-modified AuNPs for optical detection of DNA target represents an inexpensive and easy way to perform alternative assay to fluorescence or radioactivity. ${ }^{46-48}$ Recognition methods based on these materials have interesting features with respect to the enhancement of both selectivity and sensitivity as compared with many conventional tests that rely on molecular probes. This selectivity comes from the specific regions of linkage exhibited by duplex deoxyribonucleic acid (DNA) structures formed between target strands of DNA and the nanoparticles probes or single AuNPs probes hybridized to capture DNA strands immobilized on matrix. ${ }^{49}$

One application of an optical AuNPs-based DNA biosensor can be found in the genetically modified organisms (GMO) analysis. Kalogianni and co-workers ${ }^{50}$ developed a biosensor in a dipstick configuration for visual detection of GMO-related sequences (35S promoter and nopaline synthase terminator). In the present work, the migration of the buffer rehydrates the oligonucleotideconjugated AuNP, which are then coupled with the DNA target giving a characteristic colour due to the accumulation of the nanoparticles at the end of the strip.

Another interesting DNA-AuNPs optical biosensor is related to the detection and quantification of pathogens such as Helicobacter pylori, which is a bacterium that colonizes the human stomach and causes major diseases such as gastritis, peptic ulcers and stomach cancer. Gill detected Helicobacter pylori DNA by using the H. pylori ureC gene sequence for the amplification of bacterial DNA resulting in two different DNA amplicons that were thiolated and linked to AuNPs. In the optical assay when both internal probes matches perfectly the specific sequence, occurs the nanoparticle aggregation and the colour changes from red to purple indicating the presence of the bacterium DNA. ${ }^{51}$ This method showed high sensitivity and specificity in comparison to histologic studies and also reduced the time and cost needed for the molecular diagnosis of $H$. pylori. It is possible to detect as little as $10 \mathrm{CFU}$ (colony forming units) $\mathrm{mL}^{-1}$ of $H$. pylori in less than $1 \mathrm{~h}$.

AuNPs were also used to recognize and detect specific DNA sequences in a single step. Maxwell et al. ${ }^{52}$ developed nanobiosensors, where the AuNP was the core acting as both nano-scaffold and nano-quencher. Fluorophore labeled oligonucleotides were attached to AuNPs. This hybrid was found to spontaneously assemble into a constrained archlike conformation on the AuNPs surface. Binding of target molecules results in a conformational modification which restores the fluorescence of the quenched fluorophore. In this case, the gold nanocrystals have an important structural role once they interact with both thiol group and the fluorophore that are attached to the two tops of an oligonucleotide molecule. This interaction occurs on the nanometer scale and is essential for the organization of the oligos into an arch-like conformation on the particle surface.

A different optical biosensor was developed by Lee and Mirkin ${ }^{53}$ to detect $\mathrm{Hg}^{2+}$ in lake water based on the selective binding of a thymine-thymine mismatches through thymine- $\mathrm{Hg}^{2+}$-thymine complex formation upon the surface of DNA/AuNPs probes. In order to improve the scanometric detection silver was deposited upon AuNP probes in a core-shell system. The chip-based scanometric method was able to discriminate mercuric ion from fifteen other environmental relevant metal ions. In addition, the nanoparticle-target complex enhances the sensitivity attributed to the scanometric method due to the existence of a cooperative effect between AuNPs and perfect complementary strands (Figure 2). The authors called this effect as catalytic once AuNPs promote an effective hybridization of complementary strands due to the multiple duplex interconnections between the network structures.

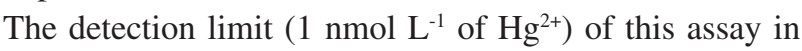
lake water samples is according to the U.S. Environmental Protection Agency (EPA). ${ }^{54}$

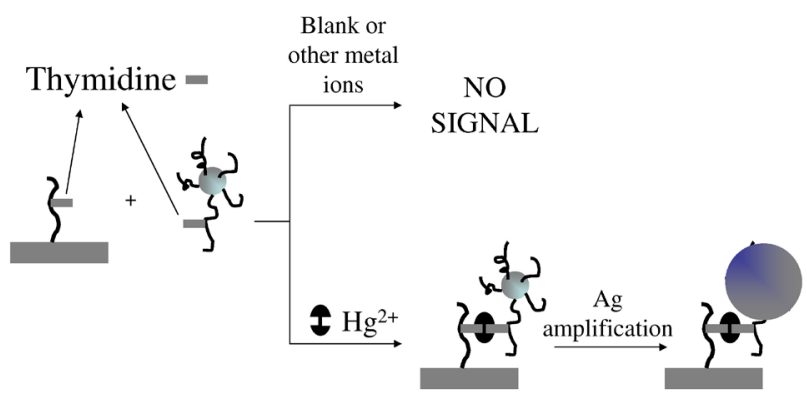

Figure 2. Scanometric DNA assay. Immobilization of capture probes on electrode. (b) Hybridization with target DNA and labeled detection probe. (c) Amplification by reductive deposition of Ag followed by scanometric detection. Adapted from reference 53.

Some short single stranded DNA or RNA sequences, known as aptamers, can specifically recognize non-nucleic acid targets such as small molecules, metal ions, proteins, whole cells and even viral particles. Functional DNA/RNA has great technological importance due to their potential use in diagnostics, especially in biosensing. DNAzymes and aptamers are collectively called functional DNAs. ${ }^{54-57}$ DNAzymes and RNAzymes are synthetic DNA-based biocatalysts or naturally occurring RNA molecules able to perform the same reactions like the protein enzymes, respectivelly. There are also a third functional DNA/RNA build up from the combination of a DNA/RNAzymes and an aptamer, the aptazyme that is an alosteric DNA/ RNAzyme. ${ }^{56}$ 
The recognition highly specific of any analyte is possible by functional DNA/RNA due to the development of a powerful combinatorial biology technique called "in vitro selection" or "systematic evolution of ligands by exponential enrichment" (SELEX) ${ }^{58-60}$ The combination of the SELEX technology with the nanotechnology of DNA/ RNA functionalized with AuNPs is an opportunity to design high performance bioanalytical devices to discriminate a wide range of analytes.

There are great revision papers about the association of AuNPs with functional DNA/RNA in biosensing reported in the literature. ${ }^{54-57,60-62}$ The label-free functional DNA/RNAbased biosensors belong to a class particularly interesting of bioanalytical devices that is emerging in the latest developments and it is going to be summarized in this section.

The intense colors exhibited by AuNPs solutions were related to the colloidal surface plasmon resonance phenomenon and are related to size, shape and local environment of the nanoparticles. ${ }^{9}$ Tamiya et al. ${ }^{63}$ explored the label-free detection of aptamer-protein interactions through the combination of localized SPR with interferometry in the relative reflected intensity spectrum of the gold-capped oxide nanostructure; in this case, gold structures provided an enhancement of the localized SPR optical properties. The excitation of the optical characteristics and the detection were performed using only one optical fiber coupled to a chip that was previously modified with a thiolated TBA (thrombin-binding aptamer). The sandwich-type detection was employed and large dynamic ranges with a high sensitivity were verified. The biosensor represents an alternative for the development of handheld diagnostic device.

By using SPR detection Wang and Zhou ${ }^{64}$ combined the amplifying characteristic of AuNPs with the advantage of aptamer technique to design a "pseudo" sandwich reaction for detecting small molecules. The principle of this biosensor is based on surface inhibition detection: after the aptamer immobilization on a SPR gold film, a solution with different concentrations of adenosine was added to the SPR cell changing the structure of the aptamer. Interestingly, the aptamer possessing tertiary structure could not hybridize with its AuNPs-tagged complementary ss-DNA. Thus, the change of the SPR signal based on the hybridization reaction will decrease with the increase of the number of aptamers possessing tertiary structure, which is proportional to the adenosine concentration. The biosensor possesses good sensitivity and a high selectivity for adenosine. The main goal of this work is the possibility of detection of a high range of small molecules by using specific aptamers once low weight molecules are difficult to detect by conventional SPR technique.
Several works were classified as optical biosensors because they fit the main request of a genuine biosensor: they present the recognition biomolecule intimately linked to a transducer element, the AuNPs. ${ }^{65-67} \mathrm{Liu}$ and $\mathrm{Lu}^{65,66}$ prepared optical biosensors based on the formation of aggregates of AuNPs functionalized with DNAzyme or aptazyme. In the first work, a selective lead biosensor was developed based on the aggregation of " $8-17$ " DNAzyme-AuNPs in the absence of $\mathrm{Pb}^{2+}$, resulting in a blue-colored nanoparticle assembly. On the contrary, in the presence of $\mathrm{Pb}^{2+}$, the DNAzyme catalyses the specific hydrolytic cleavage of substrate strand, which disrupts the formation of the nanoparticle assembly, resulting in a red-colored individual nanoparticles. In the later manuscript, the employed aptazyme was composed by the "8-17" DNAzyme with an adenosine aptamer motif (the specific elaborated sequence for the aptamer). In the absence of adenosine, the aptazyme is inactive and the substrate strands can serve as linkers to assemble functionalized AuNPs, resulting in a blue color. But in the presence of adenosine, the aptazyme is activated and cleaves the substrate strand, disrupting the formation of nanoparticle aggregates and changing the observed color. The performance of the biosensor was not evaluated in real samples and the effect of ions like $\mathrm{Pb}^{2+}$ could interfere in the analysis. Authors claim that the employed strategy can be used in other biosensors for many analytes of interest regardless of whether the analytes are directly involved in the cleavage reaction or not.

The effect of the microenvironment around aptamers on the colloidal stability of AuNPs in which the aptamer was tethered was recently investigated. Zhao et al. ${ }^{67}$ have studied two different aptamers (adenosine and potassium aptamer) and discovered a unique colloidal stabilization effect associated to the conformation that aptamers adopt on the AuNPs surface. On the basis of this phenomenon, optical biosensors have been developed for the detection of adenosine, $\mathrm{K}^{+}$, adenosine deaminase and its inhibitors, but just a few details about the analytical performance of each sensor was shown. The authors verified that AuNPs with attached folded aptamer structures are more stable toward $\mathrm{MgCl}_{2}$-induced aggregation than those tethered to unfolded aptamers. This effect is more significant when a DNA-spacer is incorporated between AuNPs and the aptamer or when lower aptamer surface graft densities are used. One interesting point of the current system is that the aggregation process of aptamer-modified AuNPs at high salt concentration can be halted by the addition of adenosine, and aggregation can even be partially reversed using adenosine. A compilation of approaches that studies the label-free functional DNA/RNA biosensors associated to AuNPs are summarized in Table 1. 


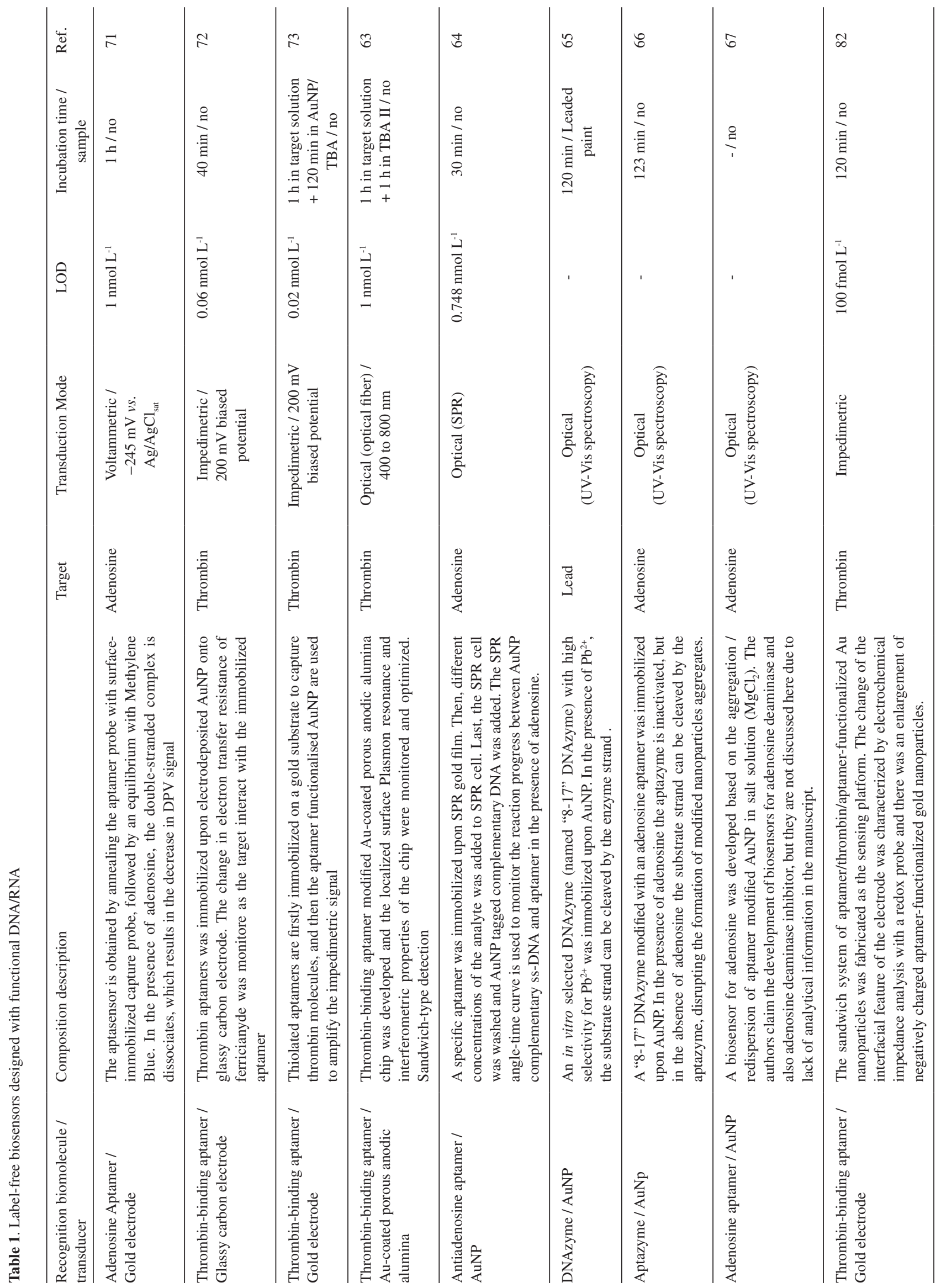




\subsection{Electrochemical}

Direct electrical detection is one of the simplest methods for bioaffinity sensing. The detection of a conductivity change can result in a detection limit of 500 femtomol $\mathrm{L}^{-1} .^{68}$ The redox properties of AuNPs have led to their extensive use in electrochemical biosensors for nucleic acid detection and other molecules, with numerous configurations being explored. ${ }^{69}$

Other materials were also used in combination with AuNPs. For example, a novel DNA biosensor has been fabricated for the DNA hybridization detection based on layer-by-layer covalent assembly of AuNPs and multiwalled carbon nanotubes. The stepwise LbL assembly was characterized by electrochemical studies showing that the presence of AuNPs was linked to a change in the film conductivity. The hybridization events of the intercalated doxorubicin were monitored by differential pulse voltammetry (DPV). The electrochemical signal increased linearly with increasing target DNA concentration from 0.01 to $0.5 \mathrm{nmol} \mathrm{L}^{-1}$ and a detection limit of $7.5 \mathrm{pmol} \mathrm{L}^{-1}$ (signal/noise ratio of 3 ) was found. ${ }^{70}$

In general label-free techniques offer several advantages over conventional ones due to the simplification of operational procedures related to the compulsory step of labeling the analyte or the receptor in a biomolecular recognition event. Several techniques sensitive to changes in interfacial properties are suited to be combined with labelfree functional DNA/RNA assays. The electrochemical approaches have been developed based on sandwich sensing and on target-induced displacement format. ${ }^{71-73}$

Yu et al. ${ }^{71}$ have developed an aptasensor with adenosine as model system based on target-induced displacement by using an external electroactive indicator methylene blue employing DPV technique. The sensing substrate comprises a gold electrode modified with a dithiol SAM that assemble an AuNPs film. A capture probe was loaded upon that nanoparticle film and an aptamer for adenosine was applied to hybridize in the presence of methylene blue, yielding a double-stranded complex. The interaction of adenosine with the aptamer displaces the aptamer sequence, which causes its dissociation from the interface releasing the electroactive indicator. This work demonstrates that the AuNPs film increases the surface loading of capture probe and, consequently, enhances the analytical signal.

An impedimetric biosensor based on a thrombin-binding aptamer as molecular recognition element was developed for the determination of thrombin. The signal enhancement was achieved by using AuNPs, which was a platform for thiolated aptamers to link. ${ }^{72}$ The biosensor monitors the linear increase of the interfacial electron transfer resistance using $\left[\mathrm{Fe}(\mathrm{CN})_{6}\right]^{3-14-}$ as the concentration of thrombin raises in the range from 0.12 up to $30 \mathrm{nmol} \mathrm{L}^{-1}$. Interestingly, the sensitivity obtained with the proposed biosensor was compared with other ones prepared upon gold disk and gold thin film coated electrodes and the authors have verified that the higher sensitivity was obtained with the former due to high surface density of thrombin-binding aptamers (TBA) immobilized on AuNPs. Another impedimetric aptasensor for thrombin was developed by Dong and et al. ${ }^{73}$ based on a sandwich sensing assay between thrombin and TBA. One thrombin molecule has two active sites, this way a sandwich protocol is easily fabricated: firstly, the thiolated TBA immobilized on gold electrode captures the analyte and then, the TBA functionalized AuNPs binds thrombin, amplifying the signal. Through such method, the detection sensitivity $\left(0.02 \mathrm{nmol} \mathrm{L}^{-1}\right)$ is higher when compared to previously reported impedimetric biosensors.

\subsection{Piezoelectric}

Enterohemorrhagic Escherichia coli $\mathrm{O} 157: \mathrm{H} 7$ is a hazardous microorganism which causes human illness by several different mechanisms. ${ }^{74-76}$ Chen et al. ${ }^{77}$ presented a nanoparticle-amplified DNA sensor using the hybridization of two specific probes using QCM. Although the mass of nanoparticles is small (a single, $10 \mathrm{~nm}$ diameter gold nanoparticle has a mass of a few attograms), nanomechanical resonator detectors are capable of sensing atto to femtogram masses of material. ${ }^{78,79}$ Nanoparticles showed substantial improvement in the detection limits with sensitivity from $10^{-12}$ up to $10^{-14} \mathrm{~mol} \mathrm{~L}^{-1}$ of $\mathrm{DNA}^{77}$ by a mass enhancement.

Since many projects are currently developing AuNPslabelled DNA/RNA probes, it seems probably that future DNA/RNA sequence detection will involve metal nanoparticle-biomolecule conjugates. For example, Qiao et al.$^{80}$ modified AuNPs using IgG and ss-DNA in a combined dual bio-probe. The surface modifications of AuNPs related to antibody and DNA attachment was evaluated by techniques such as transmission electron microscopy (TEM), UV-Vis spectra and electrophoresis. This IgG/DNA based probe brings promising perspectives of diseases detection, early tumor and heart disease, and more important is that both antibodies and ss-DNA retained their bioactivities on the nanoparticle surface. A collection of other relevant biosensors based on DNA biomolecules and AuNPs are assembled in Table 2.

AuNPs are relatively easy to synthesize are readily attached to thiol functionalities on biomolecules and they have been demonstrated to be effective labels in a number of DNA array platforms. Nanoparticles functionalized in 


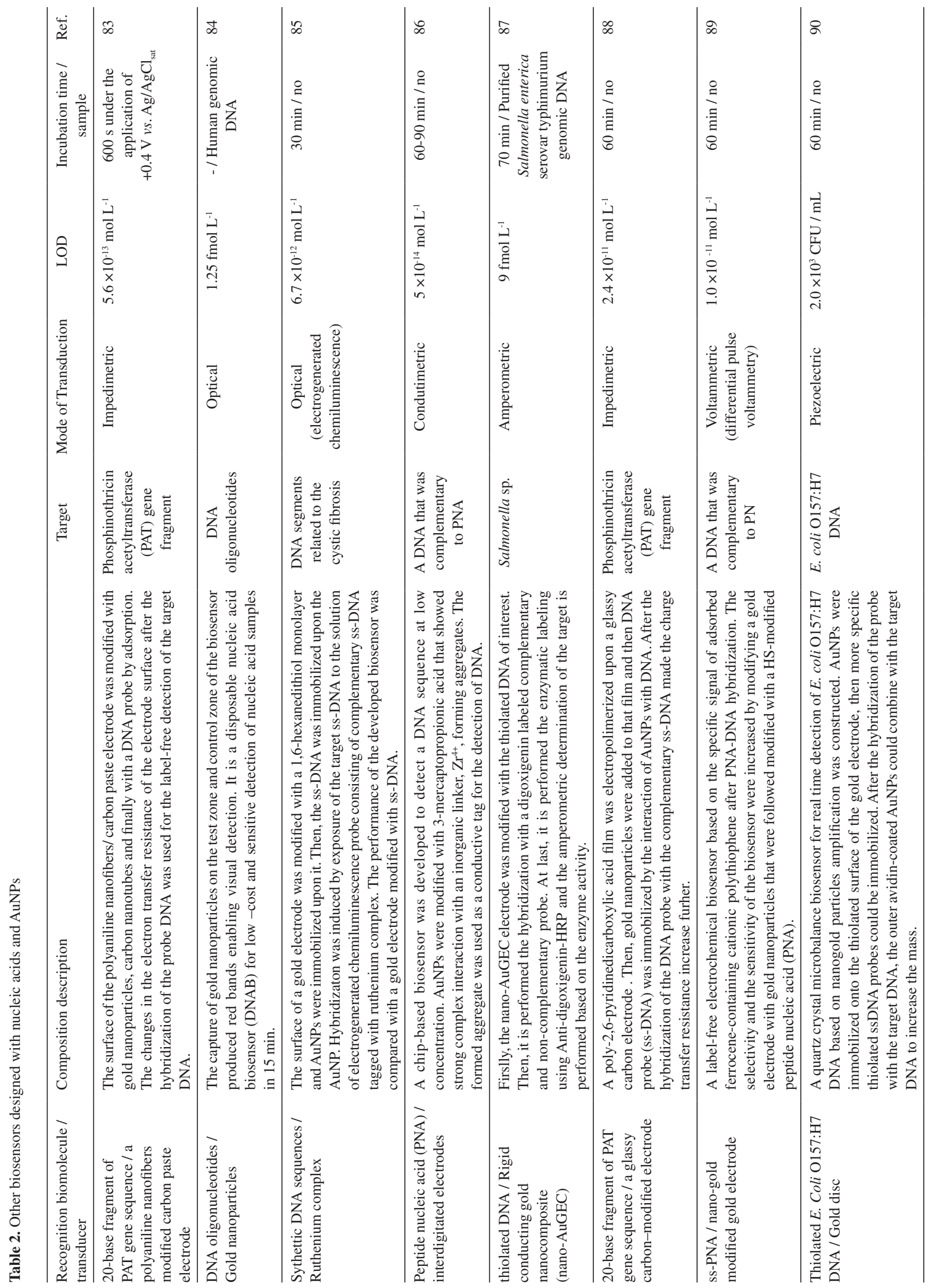


different ways have distinct features as oligonucleotide surface densities, availability for hybridization to targets and tendencies to nonspecifically bind to surfaces. ${ }^{81}$

\section{Redox Protein Biosensors Designed with AuNPs}

The enzymatic biosensor performance depends on the immobilization of the biocatalyst. In this sense, several efforts have been done in order to find an ideal arrangement to achieve high selectivity, stability, reliability and low detection limits. In this aspect, the incorporation of nanomaterials provides a huge advance, besides the great number of materials and architectures that can be tailored in an easy way. Among innumerous nanomaterials used for bioanalysis, AuNPs have a special role providing a stable immobilization of biomolecules retaining their bioactivity. Besides, AuNPs allow the enhancement of direct electron transfer between redox biomolecules and electrode surfaces, becoming the processes based on charge transfer faster and more effective. The most recent works concerning the modification of electrodes for the construction of biosensors based on redox enzymes and heme proteins are described as follow.

Among electrochemical biosensors based on enzyme attachment, certainly, the glucose oxidase (GOx) assemblies are the most studied systems. This enzyme has attractive characteristics as its well known behavior, great stability and robustness. ${ }^{91}$ As hydrogen peroxide can be formed by enzymatic reaction involving the glucose, its determination in several samples is very important for chemical, biological, clinical and other determinations, being the electrochemical methods the most employed. However, one barrier for direct electrochemical detection relies on the overpotential required for the peroxide reduction, a strategy to overcome this difficulty is the utilization of biosensors based on peroxidases..$^{92-96}$

In order to construct enzymatic electrode employing the above system, probably the simplest assembly strategy consists in incorporating nanomaterials into a composite electrode, leading to an improvement of analytical response such as low background currents. One example is the simple mixing of gold colloidal nanoparticles and carbon paste, followed by the adsorption of $\mathrm{GOx}^{97}$ or HRP, ${ }^{98}$ providing a fast electron transfer between the electrode and biomolecules.

Taking into account the large surface area promoted by nanoparticles, another strategy for electrode modification consists in a direct gold surface modification, as described by Zhang. ${ }^{99}$ In this work, gold nanoparticles were linked to gold electrode by dithiol via gold-sulphur bond, then a cystamine monolayer was chemisorbed onto AuNPs and GOx could be covalently attached to the gold electrode, resulting in a biosensing interface stable for more than 30 days. In another strategy, AuNPs were attached to hollow porous thiol-functionalized polymeric nanospheres providing an active matrix for further immobilization of HRP. ${ }^{100}$

In order to improve the spatial arrangement of nanomaterials, the sol-gel science was employed to prepare a three-dimensional network able to encapsulate both enzymes and AuNPs. Thus, the tridimensional network can acts as a tiny conducting center improving the electron transfer. ${ }^{101}$ The construction of a glucose amperometric biosensor by using this kind of modification can be made by subsequent immersion of silica modified Au electrode into different solutions: AuNPs, cysteamine and finally GOx. ${ }^{102}$ In a similar assembly, HRP was covalently attached to AuNPs immobilized on a silica network. ${ }^{103}$

Recently it was reported an interesting work involving the assembly of AuNPs and GOx in a tridimensional silica network by means of chemioluminescent reaction between the $\mathrm{H}_{2} \mathrm{O}_{2}$ produced in enzymatic reaction and luminol catalyzed by AuNPs. ${ }^{104}$ The increase of luminescent signal under different glucose concentration leads to a linear behavior from $1 \mu \mathrm{mol} \mathrm{L}-1$ up to $5 \mathrm{~m} \mathrm{~mol} \mathrm{~L}^{-1}$. The electrode modification of this work is schematically shown in Figure 3.

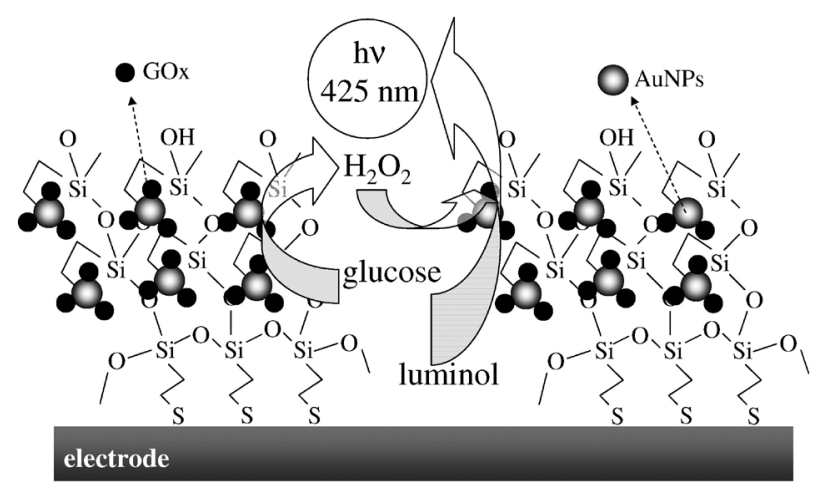

Figure 3. Principle of glucose biosensor based on gold nanoparticles and luminol. Adapted from reference 104.

Depending on its synthesis, AuNPs could present a negative charge on the surface, normally, due to citrate stabilization. This behavior can also be employed for electrode tailoring, by using the electrostatic deposition layer-by-layer (LbL) technique, reported by Detcher ${ }^{105}$ using polycations and polyanions. This method can be extended for both nanoparticles and charged biomolecules immobilization. Assemblies between nanoparticles and charged polymers were also reported in literature, for $\mathrm{SiO}_{2}$ nanoparticles and poly(diallyldimethylammonium 
chloride) (PDDA), ${ }^{106}$ Prussian blue nanoparticles ${ }^{107}$ and analogues ${ }^{108,109}$ and nickel hydroxide nanoparticles. ${ }^{110,111}$

Multilayer films of GOx/AuNPs on Au electrode surface using cysteamine as covalent attachment crosslinker, prepared by LbL technique, was performed by Yang et al. ${ }^{112}$ Bioelectrocatalytic response was directly correlated to the number of deposited bilayers, due to the amount of active enzyme immobilized on the Au surface. Another interesting electrode modification using LbL was recently reported by Crespilho et al. ${ }^{113}$ In this work, firstly the AuNPs were chemically synthesized inside dendrimers [G4-PAMAN (poly(amidoamine) dendrimers of $4^{\text {th }}$ generation)] from $\mathrm{KAuCl}_{4}$ and formic acid solutions, and then the composites were adsorbed onto ITO (indium tin oxide) electrode by alternating PAMAN-Au / PVS (poly(vinyl sulfonic) acid) bilayers. Electrocatalytic thin films of copper hexacyanoferrate were electrodeposited directly on AuNPS. Finally, enzymes were immobilized onto electrode by cross-linking method by adding a drop of a solution containing GOx, glutharaldehyde and bovine serum albumin (BSA). This electrode showed a

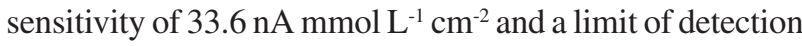
$(\mathrm{S} / \mathrm{N}=3)$ of $17 \mu \mathrm{mol} \mathrm{L} \mathrm{L}^{-1}$.

Another way to determine of glucose concentration can be made by the detection electrons generated in enzymatic reaction. But, the direct contact between the electrode and the enzymatic active site is not a simple task and the difficulty comes from the insulation of the biocatalytic redox centers by the protein organic shell. The cited assemblies of redox enzymes and AuNPs mentioned up to now already enhance the electronic transport through electrode and enzymes, but a further improvement can be achieved by the means of "molecular wiring". ${ }^{114-117}$ One of the most successful strategies for establish electrical communication between redox proteins and electrodes involve the extraction of the native redox cofactor from the protein and the reconstitution of the resultant apo-enzyme on a surface modified with a monolayer consisting of a relay tethered to the respective cofactor unity, ${ }^{118}$ bellow, in Figure 4 is shown a scheme of this method. The assembly this GOx enzymatic electrode is based on the modification of AuNPs by aminflavin adenine dinucleotide cofactor and linked to the electrode surface by dithiol molecules. Apoglucose oxidase generated by exclusion of its native FAD cofactors was reconstituted on the cofactor-modified AuNPs. The reported increase of anodic currents indicates that occur the electrical communication between its active site and the electrode. ${ }^{118,119}$ This system showed a huge heterogeneous electron transfer constant $\left(\mathrm{K}_{\mathrm{et}}\right)$ between the cofactor site and the electrode being estimated as ca. $5000 \mathrm{~s}^{-1}$, which is about seven times higher than the electron-transfer rate constant of native $\mathrm{GOx}$ with $\mathrm{O}_{2}$ as electron acceptor. Accordingly to the authors this value can be attributed to the effective contact between the electrode and the redox cofactor that stimulates the effective electron transport to the electrode by means of the AuNPs, acting as a nano-electrode, increasing the maximum turnover rate. ${ }^{119}$

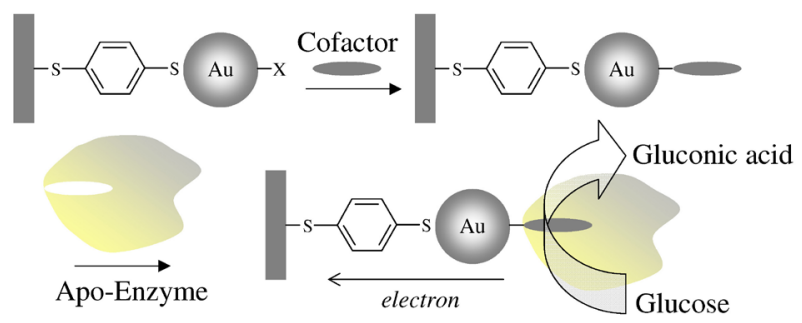

Figure 4. Electrical wiring of enzymes by the reconstitution of apoenzymes on the cofactor-functionalized AuNPs associated with electrodes. Adapted from reference 116.

Heme proteins such hemoglobin ( $\mathrm{Hb})$, myoglobin $(\mathrm{Mb})$ and cytochome c $(\mathrm{Cyt} \mathrm{c})$ do not undergo facile direct electron transfer reactions at bare electrode surfaces probably by unfavorable orientation of the redox site or due to its denaturation adsorption on the transducer. AuNPs as a biocompatible material provide an adequate microenvironment to support heme proteins for fabricating biosensors. Additionally, AuNPs have been used to achieve high uniformity and organization but with lack of restrictions in orientation of protein molecules in the biological recognition layer.

The direct heterogeneous electron transfer is possible from the protein to the transducer due to the high degree of order on a molecular level associated to the decrease of the insulating property of the protein shell promoted by the conducting tunnels made of AuNPs.

The effect of AuNPs on the electroactivity of heme proteins was mainly studied using hemoglobin and amperometric transducers as solid electrodes made of glassy carbon, gold and indium tin oxide (ITO) to a lesser degree. In general, due to their close similarities, heme proteins can be used as substitutes of peroxidases to catalyze the reduction of hydrogen peroxide, however higher potentials are required to carry out the analysis. Heme proteins associated with AuNPs have been used to build up highly sensitive biosensors for oxygen, nitrite and trichloroacetic acid. ${ }^{120-124}$ Dong et al. ${ }^{125}$ constructed a voltammetric biosensor for hydrogen peroxide based on the immobilization of $\mathrm{Hb}$ upon AuNPs assembled on sulphydryl-terminated monolayer covalently bond to the glassy carbon surface. According to authors, the immobilization of $\mathrm{Hb}$ occurred due to the specific interaction between amino-acids residues (like cysteine or 
$\mathrm{NH}_{4}{ }^{+}$-lysine of $\mathrm{Hb}$ ) and the AuNPs surface and this way, it had maintained its biological activity during two weeks.

Chen et al. ${ }^{126}$ studied the immobilization of $\mathrm{Hb}$ on AuNPs associated with a cysteamine monolayer on a gold electrode surface. The developed biosensor exhibits great electrocatalytic behaviour in the presence of $\mathrm{H}_{2} \mathrm{O}_{2}$, but retained its performance for only three weeks at $4{ }^{\circ} \mathrm{C}$. The maintenance of the bioactivity on immobilized redox proteins is an important issue that can be improved by creating a biocompatible protective environment, in this sense, the use of chitosan can be found in literature. ${ }^{127-130} \mathrm{In}$ another work, Chen et al. ${ }^{127}$ have studied the direct electron transfer and $\mathrm{H}_{2} \mathrm{O}_{2}$ electrocatalysis of $\mathrm{Hb}, \mathrm{Mb}$ and Cyt $\mathrm{c}$ immobilized onto chitosan-stabilized gold nanoparticles self-sustained on a cysteine modified gold electrode. The amperometric responses of the heme-proteins-modified electrodes were monitored at $-250 \mathrm{mV} v s$. SCE and the $\mathrm{Mb}$-modified electrode showed the best sensitivity towards $\mathrm{H}_{2} \mathrm{O}_{2}$ determination with a long-term stability attested during three months.

Another approach for the construction of an amperometric $\mathrm{H}_{2} \mathrm{O}_{2}$ biosensor with $\mathrm{Mb}$ and clay-chitosanstabilized gold nanoparticles was made by Zou et al. ${ }^{120}$ The electrocatalytic reduction of $\mathrm{H}_{2} \mathrm{O}_{2}$ was performed at $-260 \mathrm{mV} v s . \mathrm{Ag} / \mathrm{AgCl}_{\text {sat }}$ with an adequate operational stability. Interestingly, Sun et al. ${ }^{128}$ developed a simple biosensor based on the immobilization of $\mathrm{Mb}$ and AuNPs on a glassy carbon electrode using Nafion ${ }^{\circledR}$ film. The immobilized $\mathrm{Mb}$ exhibited an unmediated high electrocatalytic response to the reduction of $\mathrm{H}_{2} \mathrm{O}_{2}$ with high stability during 50 days, but on the other hand the amperometric applied potential was $-405 \mathrm{mV}$ vs. $\mathrm{Ag} / \mathrm{AgCl}_{\text {sat }}$.

Carbon nanotubes, as a new class of nanomaterials with unique electrical properties, have also been employed with AuNPs to the $\mathrm{Hb}$ immobilization in biosensors. ${ }^{121,129}$ Li et al. ${ }^{129}$ have fabricated a $\mathrm{H}_{2} \mathrm{O}_{2}$ biosensor based on the immobilization of $\mathrm{Hb}$ on multiwall carbon nanotubes and gold colloidal nanoparticles and $\mathrm{Hu}$ and $\mathrm{Liu}^{121}$ developed a similar analytical device but entrapping $\mathrm{Hb}$ in a composite electrodeposited chitosan-multiwall carbon nanotubes film by assembling gold nanoparticles and hemoglobin step by step, in both works are observed a large background current of $\mathrm{Hb} \mathrm{Fe}{ }^{\mathrm{II}} / \mathrm{Fe}^{\mathrm{II}}$ redox couple in cyclic voltammograms, low electrocatalytic towards peroxide reduction and high applied potential in amperometric monitoring. The immobilized enzyme exhibited more advantagenous analytical performance than the system without carbon nanotubes. This can be attributed to the synergistic action of both carbon nanotubes and AuNPs, since both of them have the ability to facilitate or promote the electron transfer between the proteins and the electrode surface.
AuNPs attached on ITO electrodes were applied for $\mathrm{Hb}$ and $\mathrm{Mb}$ immobilization by Oyama and Zhang. ${ }^{131,132}$ The synthesis of gold nanoparticles was based on a surfactantassisted seeding growth that was actually intended to prepare gold nanorods in solution. This synthesis provided both a short amount of rod-shaped gold nanoparticles and a large amount of spherical nanoparticles. The authors have adapted this method for ITO modification. They established a two-step electrode modification procedure. Firstly, $4 \mathrm{~nm}$ gold seeds consisted by citrate-stabilized gold nanoparticles were deposited on the ITO surface. Secondly, in a growth solution, surfactant capped gold ions were reduced when encountering the gold seeds on the electrode surface, leading to the growth of gold nanoparticles. The AuNPs attached to ITO surface was then composed by a mixture of both gold nanospheres and nanorods. It was verified a catalytic behaviour towards the reduction of $\mathrm{H}_{2} \mathrm{O}_{2}$, and no characteristic peak for $\mathrm{Hb}$ appeared in the cyclic voltammogram recorded with $\mathrm{Hb} / \mathrm{AuNP} / \mathrm{ITO}$. For $\mathrm{Mb}$, the $\mathrm{Fe}^{\mathrm{III}} / \mathrm{Fe}^{\mathrm{II}}$ redox couple also appeared in the $\mathrm{CV}$ of $\mathrm{Mb} / \mathrm{ITO}$ electrode in buffer solution. In this later case, the presence of AuNPs onto ITO has just increased the surface area for $\mathrm{Mb}$ immobilization.

Layer-by-Layer films can be constructed by using the alternate adsorption of negatively charged AuNPs and positively charged $\mathrm{Mb},\{\mathrm{AuNPs} / \mathrm{Mb}\}_{\mathrm{n}}$, on pyrolytic graphite electrode surface as described by $\mathrm{Hu}$ et al., ${ }^{122}$ where the size of AuNPs demonstrates distinct influence on the properties of the modified electrode. The smallersized AuNPs (6 nm) load more amount of Mb showing better electrochemical and biocatalytic activities toward the reduction of both $\mathrm{O}_{2}$ and $\mathrm{H}_{2} \mathrm{O}_{2}$ than those by employing larger AuNPs (40 and $90 \mathrm{~nm}$ ). Recently, Hu and Zhang ${ }^{133}$ have assembled poly(propyleneimine)-Au nanoclusters and $\mathrm{Mb}$, forming \{PPI-AuNP/Mb $\}_{\mathrm{n}}$ (poly(propyleneimine)) multilayered films. This novel kind of inorganic-organic hybrid film with dendrimer stabilized gold colloids showed better electrochemical behaviour and catalytic performance than the previously reported biosensor.

Scheller et al. ${ }^{134}$ studied the adsorption and the electrochemical behavior of Cyt $\mathrm{c}$ on AuNPs modified carbon paste electrodes. The authors claim that the presence of AuNPs was essential to avoid denaturation as well as for the stable redox transformation of adsorbed Cyt c, however this system persists stable for just two days at $4{ }^{\circ} \mathrm{C}$. The direct electron transfer of the protein to the electrode was obtained with success, but showing a restricted electrocatalysis for the reduction of $\mathrm{H}_{2} \mathrm{O}_{2}$, promoted by Cyt $\mathrm{c}$.

Some authors believe that when the adsorption of protein molecules is restricted to a monolayer or less of coverage, 


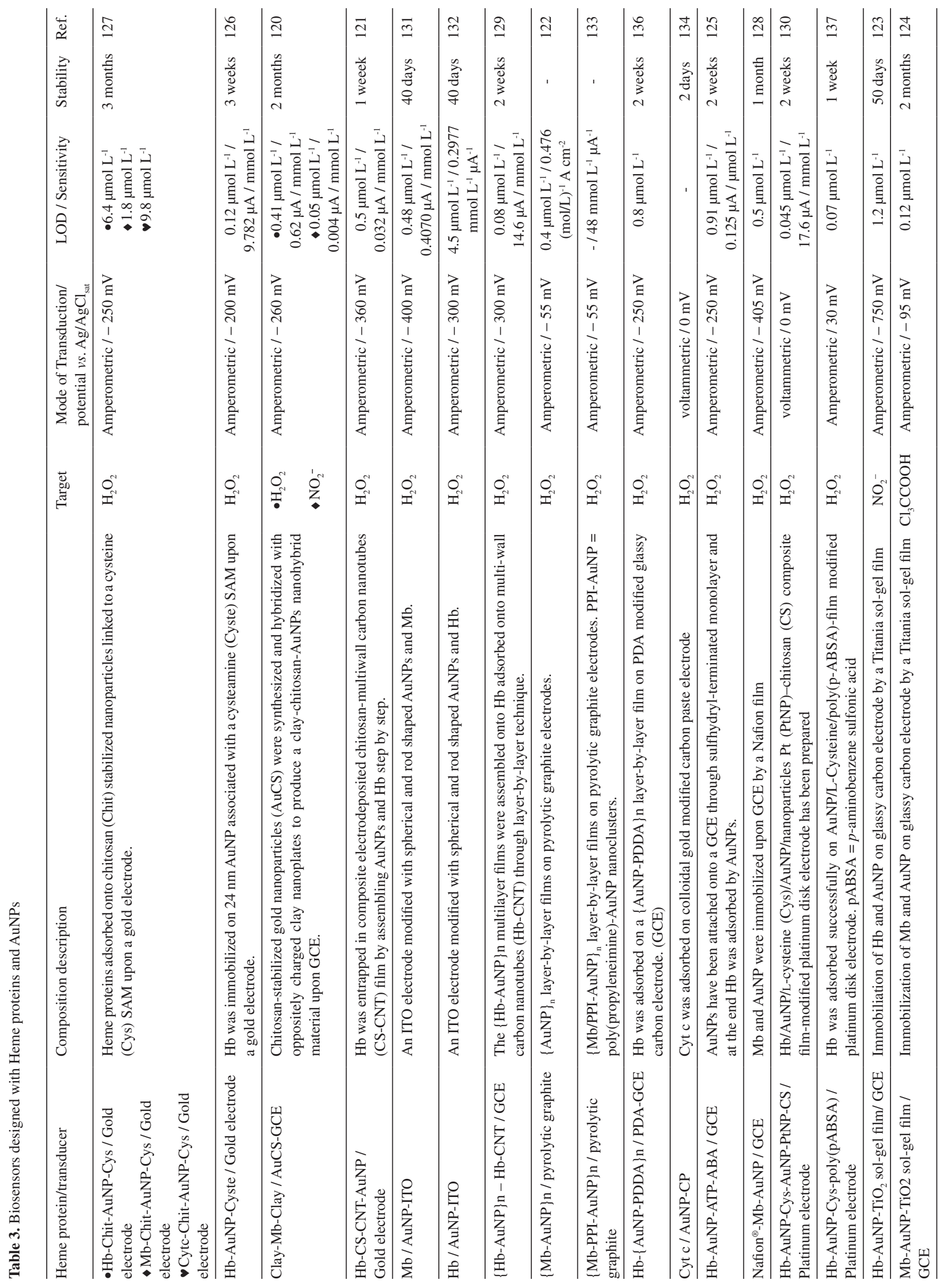


the analytical signal from the protein layer is restricted to a relatively low signal-to-background ratio, thus in some cases interfacial heterogeneity can result in superior protein adsorption at a surface. This way, assembled films of nonaqueous nanoparticles known as monolayer-protected clusters (MPCs) are interesting platforms for protein monolayer adsorption. Leopold et al. ${ }^{135}$ investigated the electrochemical properties such as electron transfer rate constants of Cyt $\mathrm{c}$ at MPC films of alkanethiol-protected AuNPs. The use of hydrophilic MPCs films as a terminal film layer results in adsorptive voltammetric behavior of Cyt $\mathrm{c}$ and the electron transfer rate constant was unaffected by the large electron transfer distance introduced by MPC assemblies when compared with traditional strategies to immobilize Cyt c. A compilation of approaches to study the direct electron transfer between Heme proteins and electrode surfaces with the aid of AuNPs are summarized in Table 3.

\section{Conclusion and Future Trends}

In this review some recent advances of AuNPs-based biosensors have been addressed. Although AuNPs have been known for more than two thousand years they are still a subject of an exponentially increasing number of interests such as optical, electronic, biomedical, magnetic and catalytic applications being a very important step of the development of nanoscience and nanotechnology. This fact could be related to both easy preparations with a large number of different synthetic methods where the shape and morphology of the particles can be easily tuned and their intrinsic physical-chemical properties, which lead to exciting new improvements of well known fields of chemistry as shown for biosensors.

Fantastic sensor devices for environmental or clinical applications can be constructed by the assembly of AuNPs and biocomponents such as enzymes, DNA / RNA, antibody, cells and others. The great affinity between gold and thiols allows the decoration of nanoparticles with a great number of macromolecules. The presence of the metallic gold itself enhances the signal of many transducers based on spectroscopy, fluorescence, luminescence and electrochemical ways. Obviously these advances could be reached due to the development of characterization techniques such as SEM (scanning electron microscopy), AFM (atomic force microscopy), TEM (transmission electron microscopy), electrochemical and spectroscopy probes and others.

As stated previously, actually the development of composite inorganic-organic matrices based on nanostructures seems to be the next irreversible step in the biosensor technology where new strategies of immobilization and interfaces are currently been investigated by hundreds of laboratories around the world, anyway aspects as durability, reliability, "in vivo" measurements, reproducibility, disposal of (nano)materials and biocompatibility are issues that still need to be best researched.

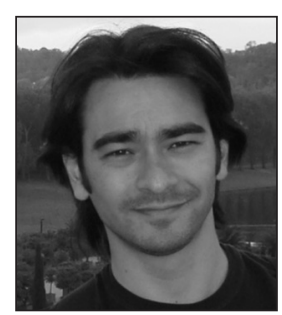

Marcio Vidotti obtained his MSc in Chemistry in 2002 and the PhD in Physical Chemistry in 2007 both from the Chemistry Institute of the Universidade de São Paulo, Brazil. Following this he held a post-doc position at the Chemistry Institute of the Universidade Estadual de Campinas, Brazil under the supervision of Prof. Kubota (2008-2009). He also worked at the University of Warwick in the labs of Profs. Julie Macpherson and Patrick Unwin (2009-2010). Currently he has a position at the Chemistry Department in the Universidade Federal do Paraná. His interests are focused on nanomaterials, polymers and electrochemical devices.

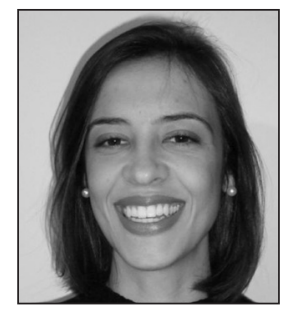

Rafaela Fernanda Carvalhal was born in 1980 in Londrina, Paraná. She graduated in Chemistry from the Universidade Estadual de Londrina in 2002 and was an internship at the Instituto Agronômico do Paraná in the laboratory of Dr. Mario Miyazawa (1999-2002). At the Universidade Estadual de Campinas she obtained her MSc in Analytical Chemistry in 2005 and she is currently a $\mathrm{PhD}$ student under supervision of Prof. Kubota at the same university. Her researches are focused on the development of disposable electrochemical devices for rapid analysis and diagnostics.

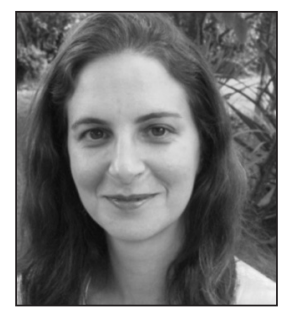

Renata Kelly Mendes graduated in Chemistry from the Universidade Federal de São Carlos and obtained her MSc in Analytical Chemistry at the same university in 2002. She received her $\mathrm{PhD}$ from the Universidade Estadual de Campinas under the supervison of Prof. Kubota. Afterwards, she held a post-doc position at the Universidade Estadual de Campinas (Brazil) under supervision of Prof. Kubota, with a stage at the Università degli Studi di Firenze, Italy. Currently, she has a position at the Pontificia Universidade Católica de Campinas and her researches are focused on bioelectrochemistry. 


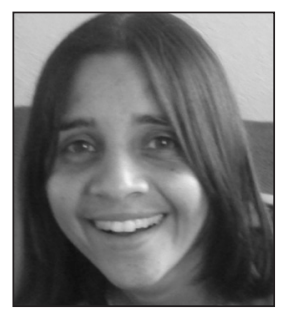

\section{Danielle Cristhina Melo}

Ferreira graduated in Chemistry from the Universidade de Alagoas. She received her MSc in Organic Chemistry from the same university, in 2004. She received a $\mathrm{PhD}$ degree in Physical Chemistry from the Universidade Federal de Alagoas and the Université Pierre et Marie Curie in 2008. Currently she is a postdoctoral fellow in Analytical Chemistry at the Universidade Estadual de Campinas under the supervision of Prof. Kubota. Her researches focus on bioelectrochemistry.

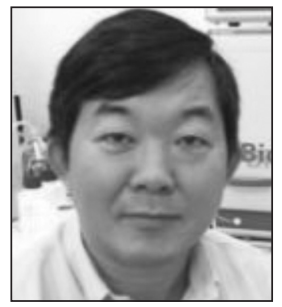

Lauro Tatsuo Kubota graduated in Chemistry from the Universidade Estadual de Londrina in 1986. He received the $\mathrm{PhD}$ degree in Chemistry from the Universidade Estadual de Campinas, in 1993. After working five years at the Universidade Estadual de São Paulo in Bauru (Brazil), he joined the Institute of Chemistry at the Universidade Estadual de Campinas, where he has been a Full Professor since 2009. He became a member of the Brazilian Academy of Science since 2010. He has published more than 230 papers in international journals, supervised $25 \mathrm{PhD}$ students and 8 post-docs. His current researches focus the development of electrochemical sensors, biosensors and bioanalytical methods.

\section{Acknowledgments}

Authors would like to thank the Brazilian agencies FAPESP and CNPq for the financial support, D. C. M. F. would like to thank FAPESP for the scholarship granted (2008/04209-3).

\section{References}

1. Trindade, T.; O’Brien, P.; Pickett, N.; Chem. Mater. 2001, 13, 3843.

2. Alivisatos, A. P.; J. Phys. Chem. 1996, 100, 13226.

3. Schoonman, J.; Solid State Ionics 2000, 135, 5.

4. Welch, C. M.; Compton, R. G.; Anal. Bioanal. Chem. 2006, 384,601 .

5. Katz, E.; Willner, I.; Wang, J.; Electroanal. 2004, 16, 19.

6. Vidotti, M.; Silva, M. R.; Salvador, R. P.; Córdoba de Torresi, S. I.; Dall’Antonia, L. H.; Electrochim Acta 2008, 53, 4030.

7. Mirkin, C. A.; Letsinger, R. L.; Mucic, R. C.; Storhoff, J. J.; Nature 1996, 382, 607.

8. Storhoff, J. J.; Mirkin, C. A.; Chem. Rev. 1999, 99, 1849.

9. Daniel, M. C.; Astruc, D.; Chem. Rev. 2004, 104, 293.
10. Mulvaney, P.; Langmuir 1996, 12, 788.

11. Alvarez, M. M.; Khoury, J. T.; Schaaff, T. G.; Shafigullin, M. N.; Vezmar, I.; Whetten, R. L.; J. Phys. Chem. B 1997, 101, 3706.

12. Damos, F. S.; Luz, R. C. S.; Kubota, L. T.; Langmuir 2005, 21, 602.

13. Mie, G.; Ann. Phys. 1908, 25, 377.

14. Qiao, F. Y.; Liu, J.; Li, F. R.; Kong, X. L.; Zhang, H. L.; Zhou, H. X.; Appl. Surf. Sci. 2008, 254, 2941.

15. Fritzsche, W.; Taton, T. A.; Nanotechnol. 2003, 14, R63.

16. Gates, A. T.; Fakayode, S. O.; Lowry, M.; Ganea, G. M.; Murugeshu, A.; Robinson, J. W.; Strongin, R. M.; Warner, I. M.; Langmuir 2008, 24, 4107.

17. IUPAC 1996 Electrochemical Biosensors: Proposed Definitions and Classification. Synopsis of report, as presented in reference 24.

18. Thévenot, D. R.; Toth, K.; Durst, R. A.; Wilson, G. S.; Biosens. Bioelectron. 2001, 16, 121.

19. Hleli, S.; Martelet, C.; Abdelghani, A.; Bessueille, F.; Errachid, A.; Samitier, J.; Hays, J. C. W.; Millner, P. A.; Burais, N.; Jaffrezic-Renault, N.; Mater. Sci. Eng. C 2006, 26, 322.

20. Jain, K. K.; Expert Rev. Mol. Diagn. 2003, 3, 153.

21. Cui, R. J.; Pan, H. C.; Zhu, J. J.; Chen, H. Y.; Anal. Chem. 2007, 79, 8494

22. Hansen, J. A.; Mukhopadhyay, R.; Hansen, J.; Gothelf, K. V.; J. Am. Chem. Soc. 2006, 128, 3860.

23. Das, J.; Aziz, M. A.; Yang, H.; J. Am. Chem. Soc. 2006, 128, 16022.

24. Yu, X.; Munge, B.; Patel, V.; Jensen, G.; Bhirde, A.; Gong, J. D.; Kim, S. N.; Gillespie, J.; Gutkind, J. S.; Papadimitrakopoulos, F.; Rusling, J. F.; J. Am. Chem. Soc. 2006, 128, 11199.

25. Wang, C.; Ma, Z.; Wang, T.; Su, Z.; Adv. Funct. Mater. 2006, $16,1673$.

26. Wu, B.Y.; Hou, S. H.; Huang, L.; Yin, F.; Zhao, Z. X.; Anzai, J. I.; Chen, Q.; Mater. Sci. Eng. C 2008, 28, 1065.

27. Lin, C. C.; Yang, Y. M.; Chen, Y. F.; Yang, T. S.; Chang, H. C.; Biosens. Bioelectron. 2008, 24, 178.

28. Xu, H.; Käll, M.; Sens. Actuat. B 2002, 87, 244.

29. Kreuzer, M. P.; Quindat, R.; Badenes, G.; Marco, M. P.; Biosens. Bioelectron. 2006, 21, 1345.

30. Kawaguchi, T.; Shankaran, D. R.; Kim, S. J.; Matsumoto, K.; Toko, K.; Miura, N.; Sens. Actuators B 2008, 133, 467.

31. Tian, Y.; Chen, Y.; Song, D.; Liu, X.; Bi, S.; Zhou, X.; Cao, Y.; Zhang, H.; Anal. Chim. Acta 2005, 551, 98.

32. Wang, Q.; Tang, H.; Xie, Q.; Jia, X.; Zhang, Y.; Tan, L.; Yao, S.; Colloids Surf. B Biointerf. 2008, 63, 254.

33. Ou, C.; Yuan, R.; Chai, Y.; Tang, M.; Chai, R.; He, X.; Anal. Chim. Acta 2007, 603, 205.

34. Tang, D.; Xia, B.; Microchim. Acta 2008, 163, 41.

35. Tang, L.; Zeng, G.; Shen, G.; Li, Y.; Zhang, Y.; Huang, D.; Environ. Sci. Technol. 2008, 42, 1207. 
36. Valera, E.; Ramón-Azcón, J.; Sanches, F. J.; Marco, M. P.; Rodríguez, A.; Sens. Actuators B 2008, 134, 95.

37. Lin, Y.; Chen, S.; Chuang, Y.; Lu, Y.; Shen, T. Y.; Chang, C. A.; Lin, C. S.; Biosens. Bioelectron. 2008, 23, 1832.

38. Zhang, L.; Liu, Y.; Chen, T.; Int. J. Biol. Macromol. 2008, 43, 165.

39. Zhang, Q.; Huang, Y.; Zhao, R.; Liu, G.; Chen, Y. J.; Colloid Interface Sci. 2008, 319, 94.

40. Zhang, Y.; Wang, H.; Yan, B.; Zhang, Y.; Li, J.; Shen, G.; Yu, R. J.; Immunol. Methods 2008, 332, 103.

41. Mohammadzadegan, R.; Mohabatkar, H.; Sheikhi, M. H.; Safavi, A.; Khajouee, M. B.; Phys. E 2008, 41, 142.

42. Blab, G. A.; Cognet, L.; Berciaud, S.; Alexandre, I.; Husar, D.; Remacle, J.; Lounis, B.; Biophys. J. 2006, 90, L13.

43. Storhoff, J. J.; Lazarides, A. A.; Mucic, R. C.; Mirkin, C. A.; Letsinger, R. L.; Schatz, G. C.; J. Am. Chem. Soc. 2000, 122, 4640.

44. Boozer, C.; Ladd, J.; Chen, S.; Jiang, S.; Anal. Chem. 2006, 78, 1515.

45. Li, H.; Rothberg, L.; Proc. Natl. Acad. Sci. U S A 2004, 101, 14036.

46. Baptista, P.; Pereira, E.; Eaton, P.; Doria, G.; Miranda, A.; Gomes, I.; Quaresma, P.; Franco, R.; Anal. Bioanal. Chem. 2008, 391, 943.

47. Li, C. Z.; Male, K. B.; Hrapovic, S.; Luong, J. H. T.; Chem. Commun. 2005, 31, 3924.

48. Storhoff, J. J.; Lucas, A. D.; Garimella, V.; Bao, Y. P.; Müller, U. R.; Nat. Biotechnol. 2004, 22, 883.

49. Jin, R.; Wu, G.; Li, Z.; Mirkin, C. A.; Schatz, G. C.; J. Am. Chem. Soc. 2003, 125, 1643.

50. Loguercio, S.; Dianb, C.; Flagiello, A.; Scannella, A.; Pucci, P.; Terradot, L.; Zagari, A.; FEBS Letters 2008, 582, 3537.

51. Gill, P.; Alvandi, A. H.; Abdul-Tehrani, H.; Sadeghizadeh, M.; Diagn. Microbiol. Infect. Dis. 2008, 62, 119.

52. Maxwell, D. J.; Taylor, J. R.; Nie, S.; J. Am. Chem. Soc. 2008, 124, 9606.

53. Lee, J. S.; Mirkin, C. A.; Anal. Chem. 2008, 80, 6805.

54. Taton, T. A.; Mirkin, C. A.; Letsinger, R. L.; Science 2000, 289 , 1757.

55. Lu, Y.; Liu, J.; Curr. Opin. Chem. Biol. 2006, 17, 580.

56. De-los-Santos-Álvarez, N.; Lobo-Castañón, M. J.; MirandaOrdieres, A. J.; Tuñón-Blanco, P.; Trends Anal. Chem. 2008, $27,437$.

57. Liu, J.; Lu, Y.; J. Fluorescence 2004, 14, 343.

58. Wilson, D. S.; Szostak, J. W.; Ann. Rev. Biochem. 1999, 68, 611.

59. Ellington, A. D.; Szostak, J. W.; Nature 1990, 346, 818.

60. Tuerk, C.; Gold, L.; Science 1990, 249, 505.

61. Kim, Y. S.; Lee, S. J.; Gu, M. B.; Biochip J. 2008, 2, 175.

62. Willner, I.; Shlyahousky, B.; Zayats, M.; Willner, B.; Chem. Rev. Soc. 2008, 37, 1077.
63. Kim, D. K.; Kerman, K.; Hiep, H. M.; Saito, M.; Yamamura, S.; Takamura, Y.; Kwon, Y. S.; Tamiya, E.; Anal. Biochem. 2008, 379,1 .

64. Wang, J.; Zhou, S. H.; Anal. Chem. 2008, 80, 7174.

65. Liu, J.; Lu, Y.; J. Fluorescence 2004, 14, 343.

66. Liu, J.; Lu, Y.; Anal. Chem. 2004, 76, 1627.

67. Zhao, W.; Chiuman, W.; Lam, J. C. F.; McManus, S. A.; Chen, W.; Cui, Y.; Pelton, R.; Brook, M. A.; Li, Y.; J. Am. Chem. Soc. 2008, 130, 3610.

68. Tansil, N. C.; Gao, Z.; Nanotoday 2006, 1, 28.

69. Pingarrón, J. M.; Yáñez-Sedeño, P.; González-Cortés, A.; Electrochim. Acta 2008, 53, 5848.

70. Ma, H.; Zhang, L.; Pan, Y.; Zhang, K.; Zhang, Y.; Electroanal. 2008, 20, 1220.

71. Feng, K.; Sun, C.; Kang, Y.; Chen, J.; Jiang, J. H.; Shen, G. L.; Yu, R. Q.; Electrochem. Commun. 2008, 10, 531.

72. Li, X.; Shen, L.; Zhang, D.; Qi, H.; Gao, Q.; Ma, F.; Zhang, C.; Biosens. Bioelectron. 2008, 23, 1624.

73. Li, B.; Wang, Y.; Wei, H.; Dong, S.; Biosens. Bioeletron. 2008, 23, 965 .

74. Food and Drug Administration (2006) FDA announces findings from investigation of foodborne Escherichia coli $\mathrm{O} 157: \mathrm{H7}$ outbreak in spinach. http://www.fda.gov/oia/Mepi/Handouts/ Spinach-Outline.pdf. Accessed 10 Jul 2010.

75. Food and Drug Administration (2006) Foodborne Pathogenic Microorganisms and Natural Toxins Handbook. http://www. cfsan.fda.gov/ mow/chap15.html. Accessed 10 Jul 2010.

76. Food and Drug Administration (2006) Waterborne Dissemination of Escherichia coli O157:H7. http://www.fda.gov/cvm/ waterborne.htm. Accessed $10 \mathrm{Jul} 2010$.

77. Chen, S. H.; Wu, V. C. H.; Chuang, Y. C.; Lin, C. S.; J. Microbiol. Meth. 2008, 73, 7.

78. Lavrik, N. V.; Datskos, P. G.; Appl. Physics Lett. 2003, 82, 2697.

79. Chiu, C. S.; Gwo, S.; Anal. Chem. 2008, 80, 3318.

80. Qiao, F. Y.; Liu, J.; Li, F. R.; Kong, X. L.; Zhang, H. L.; Zhou, H. X.; Appl. Surf. Sci. 2008, 254, 2941.

81. Fritzsche, W.; Taton, T. A.; Nanotechnol. 2003, 14, R63.

82. Deng, C.; Chen, J.; Nie, Z.; Wang, M.; Chu, X.; Chen, X.; Xiao, X.; Lei, C.; Yao, S.; Anal. Chem. 2009, 81, 739.

83. Zhou, N.; Yang, T.; Jiang, C.; Du, M.; Jiao, K.; Talanta 2009, 77, 1021.

84. Mao, X.; Ma, Y.; Zhang, A.; Zhang, L.; Zeng, L.; Liu, G.; Anal. Chem. 2009, 81, 1660.

85. Li, Y.; Qi, H.; Yang, J.; Zhang, C.; Microchim. Acta 2009, 164, 69.

86. Fang, C.; Fan, Y.; Kong, J.; Gao, Z.; Balasubramanian, N.; Anal. Chem. 2008, 80, 9387.

87. Marques, P. R. B. O.; Lermo, A.; Campoy, S.; Yamanaka, H.; Barbé, J.; Alegret, S.; Pividori, M. I.; Anal. Chem. 2009, 81, 1332.

88. Yang, J.; Yang, T.; Feng, Y.; Jiao, K.; Anal. Biochem. 2007, 365, 24. 
89. Fang, B.; Jiao, S.; Li, M.; Qu, Y.; Jiang, X.; Biosens. Bioelectron. 2008, 23, 1175 .

90. Jiang, W. L.; Shan, W. Q.; Sheng, W. C.; Ying, H. Z.; Jian, J.; Ping, W.; Chin. Sci. Bull. 2008, 53, 1175.

91. Wang, J.; Electroanal. 2001, 13, 983.

92. Hurdis, E. C.; Romeyn, J. H.; Anal. Chem. 1954, 26, 320.

93. Hanaoka, S.; Lin, J. M.; Yamada, M.; Anal. Chim. Acta 2001, $426,57$.

94. Wollenberger, U.; Wang, J.; Ozsoz, M.; Scheller, F.; Bioelectrochem. Bioenerg. 1991, 26, 287.

95. Xiao, Y.; Ju, H. X.; Chen, H. Y.; Anal. Biochem. 2000, 278, 22.

96. Zhao, J.; Henkens, R. W.; Stonehuerner, J.; O’Daly, J. P.; J. Electroanal. Chem. 1992, 327, 109.

97. Li, S.; Ju, H.; Biosens. Bioelectron. 2003, 19, 177.

98. Liu, S. Q.; Ju, H. X.; Anal. Biochem. 2002, 307, 110.

99. Zhang, S.; Wang, N.; Yu, H.; Niu, Y.; Sun, C.; Bioelectrochem. 2005, 67, 15.

100. Xu, S.; Peng, B.; Han, X.; Biosens. Bioelectron. 2007, 22, 1807.

101. Bharathi, S.; Nogami, M.; Ikeda, S.; Langmuir 2001, 17, 1.

102. Zhang, S.; Wang, N.; Niu, Y.; Sun, C.; Sens. Actuators B 2005 , 109, 367.

103. Jia, J.; Wang, B.; Wu, A.; Cheng, G.; Li, Z.; Dong, S.; Anal. Chem. 2002, 74, 2217.

104. Liu, X.; Niu, W.; Li, H.; Han, S.; Hu, L.; Xu, G.; Electrochem. Commun. 2008, 10, 1250.

105. Decher, G.; Science 1998, 277, 1232.

106. Lvov, Y. M.; Rusling, J. F.; Thomsen, D. L.; Papadimitrakopoulos, F.; Kawakami, T.; Kunitake, T.; Chem. Comm. 1997, 11, 1229.

107. Fiorito, P. A.; Gonçales, V. R.; Ponzio, E. A.; Córdoba de Torresi, S. I.; Chem. Commun. 2005, 3, 366.

108. Baioni, A. P.; Vidotti, M.; Fiorito, P. A.; Ponzio, E. A.; Córdoba de Torresi, S. I.; Langmuir 2007, 23, 6796.

109. Baioni, A. P.; Vidotti, M.; Fiorito, P. A.; Córdoba de Torresi, S. I.; J. Electroanal. Chem. 2008, 622, 219.

110. Vidotti, M.; Greco, C. V.; Ponzio, E. A.; Córdoba de Torresi, S. I.; Electrochem. Commun. 2006, 8, 554; Vidotti, M.; Salvador, R. P.; Ponzio, E. A.; Córdoba de Torresi, S. I.; J. Nanosci. Nanotechnol. 2007, 7, 3221.

111. Vidotti, M.; Salvador, R. P.; Córdoba de Torresi, S. I.; Ultrason. Sonochem. 2009, 16, 35.

112. Yang, W.; Wang, J.; Zhao, S.; Sun, Y.; Sun, C.; Electrochem. Commun. 2006, 8, 665.

113. Crespilho, F. N.; Ghica, M. E.; Florescu, M.; Nart, F. C.; Oliveira Jr, O. N.; Brett, C. M. A.; Electrochem. Commun. 2006, 8, 1665.
114. Yang, M.; Jiang, L. Y.; He, Y.; Shen, G.; Yu, R.; Biomater. 2007, 28, 3408 .

115. Willner, B.; Katz, E.; Willner, I.; Curr. Opin. Biotechnol. 2006, 17,589 .

116. Willner, I.; Willner, B.; Katz, E.; Bioelectrochem. 2007, 70, 2.

117. Willner, I.; Katz, E.; Angew. Chem. Int. Ed. 2000, 39, 1180.

118. Willner, I.; Heleg-Shabtai, V.; Blonder, R.; Katz, E.; Tao, G.; Buckmann, A. F.; Heller, A.; J. Am. Chem. Soc. 1996, 118, 10321.

119. Xiao, Y.; Patolsky, F.; Katz, E.; Hainfeld, J. F.; Willner, I.; Science 2003, 299, 1877.

120. Zhao, X.; Mai, Z.; Kang, X.; Dai, Z.; Zou, X.; Electrochim. Acta 2008, 53, 4732.

121. Liu, C.; Hu, J.; Electroanal. 2008, 10, 1067.

122. Zhang, H.; Lu, H.; Hu, N.; J. Phys. Chem. 2006, 110, 2171.

123. Yang, W.; Bai, Y.; Li, Y.; Sun, C.; Anal. Bioanal. Chem. 2005, $382,44$.

124. Li, Y.; Yang, W.; Bai, Y.; Sun, C.; Electroanal. 2006, 18, 499.

125. Zhang, L.; Jiang, X.; Wang, E.; Dong, S.; Biosens. Bioelectron. 2005, 21, 337.

126. Gu, H. Y.; Yu, A. M.; Chen, H. Y.; J. Electroanal. Chem. 2001, 516,119 .

127. Feng, J.; Zhao, G.; Xu, J.; Chen, H.; Anal. Biochem. 2005, 342, 280.

128. Yang, W.; Li, Y.; Bai, Y.; Sun, C.; Sens. Actuators B 2006, 115, 42.

129. Chen, S.; Yuan, R.; Chai, Y.; Zhang, L.; Wang, N.; Li, X.; Biosens. Bioelectron. 2007, 22, 1268.

130. Yang, G.; Yuan, R.; Chai, Y.; Colloid Surf. B Biointerf. 2008, $61,93$.

131. Zhang, J.; Oyama, M.; Electrochim. Acta 2004, 50, 85.

132. Zhang, J.; Oyama, M.; J. Electroanal. Chem. 2005, 577, 273.

133. Zhang, H.; Hu, N.; Biosens. Bioelectron. 2007, 23, 393.

134. Ju, H.; Liu, S.; Ge, B.; Lisdat, F.; Scheller, F. W.; Electroanal. 2002, 14, 141.

135. Loftus, A. F.; Reighard, K. P.; Kapourales, S. A.; Leopold, M. C.; J. Am. Chem. Soc. 2008, 130, 1649.

136. Tang, D.; Xia, B.; Zhang, Y.; Microchim. Acta 2008, $160,367$.

137. Gao, F.; Yuan, R.; Chai, Y.; Tang, M.; Cao, S.; Chen, S.; Colloid Surf. A Physicochem. Eng. Aspects 2007, 295, 223.

Submitted: July 19, 2010

Published online: November 9, 2010

FAPESP has sponsored the publication of this article. 